\title{
The Evolution and Determinants of Interorganizational Coinvention Networks in New Energy Vehicles: Evidence from Shenzhen, China
}

\author{
Jia Liu, ${ }^{1}$ Zhaohui Chong $\mathbb{D}^{2}{ }^{2}$ and Shijian $\mathrm{Lu}^{3,4}$ \\ ${ }^{1}$ School of Economics, Guangdong University of Finance and Economics, Guangzhou 510320, China \\ ${ }^{2}$ Business School, Shantou University, Shantou 515063, China \\ ${ }^{3}$ School of Chemistry and Chemical Engineering, Liaocheng University, Liaocheng 252000, China \\ ${ }^{4}$ Sinopec Petroleum Engineering Corporation, Dongying 257026, China \\ Correspondence should be addressed to Zhaohui Chong; zhchong@stu.edu.cn
}

Received 13 November 2020; Revised 28 December 2020; Accepted 16 January 2021; Published 31 January 2021

Academic Editor: Wei Zhang

Copyright (C) 2021 Jia Liu et al. This is an open access article distributed under the Creative Commons Attribution License, which permits unrestricted use, distribution, and reproduction in any medium, provided the original work is properly cited.

\begin{abstract}
With the increasing attention to climate change, air pollution, and related public health issues, China's new energy vehicles (NEVs) industry has developed rapidly. However, few studies investigated the evolution of interorganizational collaborative innovation networks in the sector domain of NEVs and the influence of different drivers on the establishment of innovation relationships. In this context, this paper uses the joint invention patent of Shenzhen, a low-carbon pilot city of China, to investigate the dynamics of network influencing factors. The social network analysis shows that the scale of coinvention network of NEVs is constantly increasing, which is featured with diversified cooperative entities, and collaboration depth (i.e., the intensity of the interactions with these partners) is also expanding. The empirical results from the Exponential Random Graph Model (ERGM) demonstrate that, with the deepening of collaborative innovation, technological upgrading caused by knowledge exchange makes organizations in the network more inclined to cognitive proximity and less dependent on geographical proximity. In addition, organizational proximity and triadic closure contribute positively to the collaborative network, with their relevance remaining nearly the same, while the impeding effect of cultural/language difference is slightly decreasing with time.
\end{abstract}

\section{Introduction}

The promotion and development of new energy vehicles (NEVs) is not only a strategic choice to reduce emissions containing atmospheric pollutants, but also an inevitable need for the development of a low-carbon economy [1-3]. Many countries have released preferable policies to support their application such as free vehicle plates, governmental subsidies, rapid development of charging stations, and cheaper insurance fees [4]. The development of China's NEVs industry began in the early twenty-first century. Since the launch of the "863" major electric vehicle project in 2001, the national and local governments have constantly introduced relevant policies to promote the development of NEVs. In 2010, the NEVs industry was listed in China's seven strategic emerging industries. In the " $13^{\text {th }}$ five-year plan for the development of strategic emerging industries" issued by the State Council in 2016, it pointed out to cultivate green and low-carbon industries such as NEVs into pillar industries. A series of policies reveal that China's NEVs industry is facing unprecedented opportunities.

As a representative of the emerging industry, NEVs adopt emerging technologies and the core of their industrial competitiveness depends on technological innovation $[5,6]$. Due to the complexity of technology and the high cost and uncertainty of innovation, innovation subjects are gradually shifting from independent research and development (R\&D) to cooperative innovation, so as to realize the sharing of innovation resources, cost reduction, and risk diversification [7]. As the main carrier of the transformation of scientific 
and technological achievements in the process of cooperative innovation, patent application, to a large extent, represents the innovation ability of a firm's R\&D capacity. A large amount of literature has explored patent cooperation in the high-tech industry. Lei et al. [8] studied the overall situation of patent cooperation of Taiener battery by elaborating three different types of cooperation, and the changing trend of cooperation mode. Omelianenko [9] analyzed the necessity of establishing diplomatic relations and mutual relations between clusters and further proposed that international partnership development between clusters is the most appropriate form for developing cooperation between high-tech sectors.

With the acceleration of network research, the collaborative innovation network of high technology has attracted extensive attention. Choe et al. [10] studied the structure and characteristics of knowledge flow among countries, institutions, and technologies in the field of organic photovoltaic cells. Zheng et al. [11] analyzed the development of international cooperation in nanotechnology by using a patent network. Sun and Liu [12] established a multilayer network model of intraregional and interregional joint patent research and applied the model to China context. De Paulo et al. [13] studied photovoltaic technology patents and cooperation according to the structure and interaction among national clusters. Generally, studies on the outline of these collaborative research networks, especially at the interorganizational level, remain few and far between.

With regard to the development of the electric vehicle industry, several studies focus on patents and technological innovation for NEVs. For instance, taking Japan as an example, Ahman [14] discussed the relationship of government policy and the development path of the electric vehicle. Based on a comparative analysis of the entire invention patents and joint patents, Wang and Zhu [15] examined patents development in China's NEVs industry from the perspective of industry-university-institute cooperation. Christensen [16] argued that sharing components of power transmission systems, such as battery power systems, hybrid power, and fuel systems, is of great help to implement the modular strategy. However, most of the existing research on patents of NEVs industry address the technology development trend [17] and the driving forces of industrial development $[18,19]$. Notable exceptions in this respect included and the studies of Sun et al. [20] studied the characteristics of patent cooperation network based on the top 38 organizations with the most NEV-related patents as research objects, and the study of Cao et al. [21] established technological cooperation innovation network and analyzed the invincibility and optimization process of the network. The role of proximity in favoring the transmission of knowledge in innovation and interorganizational networks has also received increasing attention recently [22-27]. Despite this, existing studies find little evidence about the evolution of geographical or nongeographical factors in the formation of such networks [28].

The aim of this study is to investigate the impact of the different relationships between partners for the establishment of innovation linkages in Shenzhen's NEVs industry.
This paper expands the existing literature on two aspects. First, it explores the evolutionary path of topological structure and spatial patterns of interorganizational innovative collaboration in NEVs industry. Second, in contrast to most literature on a static or certain type of influential factors [29, 30], the paper provides an explanation for the evolutionary mechanism of interorganizational innovative networks. For this purpose, we analyze the determining factors employing the Exponential Random Graph Model (ERGM) which can combine the endogenous structures and the exogenous factors [31]. Hence, we could distinguish between different types of determinants to confirm how the significance and magnitude of the influential factors change.

In particular, Shenzhen is chosen as the study area to inspect and analyze interorganizational coinvention network of NEVs. In an attempt to promote the implementation of China's greenhouse gas emissions control target, Shenzhen was offered as the pilot low-carbon city in 2010 and has reduced carbon emissions by more than 200,000 tones annually due to the implementation of lowcarbon transportation and construction projects [32]. In addition, the local government has set up a special fund for the development of NEVs industry since low-carbon city construction, making the focal area an archetypal location for interorganizational coinvention network of NEVs research.

The remainder of the paper is structured as follows: Section 2 discusses the theoretical foundation of potential determinants of interorganizational knowledge collaboration and formulates several hypotheses. Section 3 describes the data collection followed by introducing the theoretical network model. Network characteristic evolution based on respective network indicators is presented in Section 4, while, in Section 5, we report and interpret the empirical results; and the final section concludes the paper.

\section{Research Hypotheses}

In this work, we mainly focus on four commonly identified types of geographical and nongeographical proximity in the development of NEVs networks, including geographical, cognitive, organizational, and cultural factors.

Geographical proximity indicates the degree of proximity of spatial distance between enterprises, and it is regarded as a prerequisite for enterprises in a cluster to pursue knowledge externality [33]. On the one hand, geographical proximity reduces the cost of transportation and communication between enterprises, thereby facilitating the transfer and learning of tacit knowledge. On the other hand, it provides opportunities for frequent face-to-face communication among enterprises and helps to enhance mutual trust and understanding among enterprises, especially for highly skilled workers [34]. However, despite the tendency for spatial agglomeration of innovation activities, the number of interregional R\&D collaborations has increased markedly as well $[35,36]$. They believe that permanent colocation within a cluster is not necessary, and the excessive proximity of partners will bring certain negative effects such as lock-in, a situation in which inventors successively create 
technologies of the same type, industrial structures [37]. In the early stage of the development of NEVs coinvention network, companies benefit from geographical proximity in space and conduct extensive short-distance collaborations [38]. With the continuous development of technology and industry, cooperation between companies is not limited to proximity in space. Long-distance collaboration is often more valuable and involves the exchange of knowledge in high-level technological fields. Therefore, we test the following hypothesis.

Hypothesis 1. Geographical distances impede upon research collaboration between Shenzhen and other cities, and the effect is diminishing over time in importance.

Cognitive proximity is a particularly important element for promoting innovation. Coinvention requires an appropriate capacity to absorb new knowledge, which requires the establishment of a homogeneous cognitive basis [39]. Neither very small nor large cognitive distances result in good outputs and learning effects in the interactions [40]. On the one hand, the development of new technology is more and more based on the combination of remote technological fields [41], as it helps generate new knowledge and radical innovations and avoid cognitive lock-in. On the other hand, the amount of knowledge grows exponentially. Even with intensive and interdisciplinary education, the proportion of everyone in the overall knowledge is declining, so it is necessary to work with collaborators who have minor cognitive distance [42]. In the embryonic development period of NEVs industry, most enterprises are making exploratory attempts. Firms and other organizations primarily form ties with other actors that share the same knowledge base and competencies since establishing relations between different knowledge bases are more difficult. For these reasons, we assume the increased specialization outweighs the increased interdisciplinarity in the innovative collaboration of NEVs and state.

Hypothesis 2. The positive relationship of cognitive proximity, with the probability of a coinvention link between two organizations, remains stable over time.

Organizational proximity refers to rules and procedures that connect enterprises to the same organizational framework, reflecting the degree of sharing of relationships within and between organizations [31]. Similar rules and incentive mechanisms among enterprises help to manage knowledge exchange and reduce transaction costs. In addition, organizations need strong control mechanisms to ensure their ownership of new technologies and adequate returns. However, excessive organizational proximity may also limit interactive learning and flexibility between organizations. Based on the constraints of the same organizational framework, the possibility of establishing cooperative relations between parent corporations and subsidiaries is much higher than that of general enterprises. Therefore, we will test the following hypothesis.

Hypothesis 3. Organizational proximity plays an important role in the establishment of innovative collaborations between organizations, and its importance remains stable over time.

Apart from the above proximity affecting coinvention activities, the transmission of knowledge is easier when individuals and companies share a common language and similar cultural and religious values [39]. Regarded as informal institutional proximity, cultural/linguistic proximity can increase trust and lower transactions costs, assisting in the generation and diffusion of collaborative ideas.

In China, regional dialects are quite prevailing in their respective areas and act as an important factor of cultural identity $[43,44]$. The complexity of Chinese dialects is parallel in many respects with the Roman family in Europe [45]. Different linguistic areas are therefore supposed to intensify the fragmentation of the research networks between Shenzhen and other cities. However, as both the Chinese central government and the local government in Shenzhen have promulgated a set of policies aiming to strengthen the position of Shenzhen as a national scientific center and knowledge linkages to the globe, Shenzhen has established branches of many renowned URIs at the national and global scale, such as Peking University, Harbin Institute of Technology, and Moscow State University. In addition, it has launched its "Peacock Plan" in 2011 to attract overseas talent to work in the city. We assume that these projects could facilitate cultural proximity in the long run. Hence, we will test the following hypothesis.

Hypothesis 4. The negative relationship of cultural/linguistic differences with the probability of a coinvention link between two organizations decreases over time.

\section{Data and Methodology}

3.1. Data. Through the patent information inquiry system of China National Intellectual Property Administration, the paper takes the applicant's address and the new energy vehicle keywords as the screening conditions and uses custom Python scripts designed to crawl the specific coinvention patent data whose at least one of the coinventors is located at Shenzhen from 2006 to 2017. The new energy vehicle keywords include electric vehicles, new energy, new energy vehicles, charging piles, hybrid, intelligent vehicles, new energy batteries, electronic controls, automobile motors, and automobile safety. The paper has extracted 1351 NEVs coinvention patent data involving 2 or more inventors in the study period.

\subsection{Methods}

\subsubsection{Network Index}

(1) Network Density. Network density reflects the overall connectivity level by dividing the number of actual ties by the number of maximum possible ties. A higher network density means a higher degree of connectivity between node cities in the network. Using $V_{1}$ to denote the number of 
actual ties in the network with $N$ cities, network density $D_{N}$ can be expressed as

$$
D_{N}=\frac{V_{1}}{(N \times(N-1) / 2)} .
$$

(2) Centrality. Centrality measures the importance of a node city in the network. Although there are as many as thirty centrality indicators, the degree of centrality is considered to be the indicator that most directly reflects the location of the node network by focusing on the number of ties an organization has $[46,47]$. In equation (2), $C_{i}$ denote the degree centrality of organization $i$ and $l_{i j}$ denote the ties from organization $i$ to organization $j$ :

$$
C_{i}=\frac{\sum_{j=1, j \neq i}^{N} l_{i j}}{(N-1)} .
$$

Eigenvector centrality is to find the node with the most central position on the basis of the overall network structure. Its basic principle is to identify the dimension of the distance between network nodes. Each node has a position on each dimension, which is an eigenvalue, and all eigenvalue sets are eigenvectors.

3.2.2. The ERGM Specification. ERGM is a statistical model to analyze the factors affecting network formation [48]. By abstracting and modeling social networks, ERGM can express the influence of network links and character attributes on social networks. The main advantage of ERGM lies in its capacity to analyze the dependence among nodes on the formation of a network [49].

The specification of ERGM can be set as

$$
\operatorname{Pr}(Y=y)=\left(\frac{1}{k}\right) \exp \left\{\sum_{A} \eta_{A} g_{A}(y)\right\},
$$

where $A$ denotes all possible network configurations and $\eta_{A}$ is its corresponding parameter; $g_{A}(y)=\prod_{(i, j) \in A} y_{i j}$ represents the network statistic corresponding configuration which obtains a value of 1 when it is observed in $y . k$ is a normalizing constant which ensures the distribution of equation (3).

Another advantage of ERGM is that it can simultaneously consider structural network level factors, as well as node and dyad level factors, which correspond to the three parts of the network configuration [50]. The general form of ERGM that includes the three kinds of factors can be specified as follows:

$$
\operatorname{Pr}(Y=y)=\left(\frac{1}{k}\right) \exp \left\{\eta_{\alpha} g_{\alpha}(y)+\eta_{\beta} g_{\beta}(y)+\eta_{\gamma} g_{\gamma}(y)\right\} .
$$

The parameters $(\alpha, \beta, \gamma)$ signify the significance and importance of selected factors. The estimation of the parameters is done with the Markov Chain Monte Carlo method using $R$ software.

\section{The Network Characteristic and Evolutionary Pattern}

4.1. StructuralEvolution Analysis. To illustrate the dynamics of the collaborative network, we divide the sample into three periods of roughly equal length: 2006-2009, 2010-2013, and 2014-2017. In addition, $R$ software is used to draw the topology evolution diagram of the collaboration network. As shown in Figure 1, the connection line represents the cooperative relationship between the patent applicants in the coinvention network of NEVs. The larger node suggests the more collaborators it has, and the thicker the connection line, the more frequent cooperation between the nodes.

In the first period, from 2006 to 2009 , the network is in the initial stage of formation and the amount of patent cooperation is relatively small. With the development of NEVs industry, universities and enterprises begin to exchange knowledge, technology, and resources and gradually develop a cooperative relationship with each other. At this stage, patent cooperation mainly occurs between enterprises. For example, Hongfujin Precision Industry (Shenzhen) Co., Ltd. establishes a stable partnership with HonHi Precision Industry. Fugang Electronic (Dongguan) Co., Ltd. and Cheng Uei Precision Industry Co., Ltd. are also frequent collaborators.

The cooperative network develops into the expansion stage during the period of 2010-2013, reflecting an increasing number of organizations carrying out collaborative innovation activities carry out innovative activities. It is notable that cooperation between universities and enterprises is on the rise, which entails the frequent flow of knowledge, technology, and other resources in the network. For instance, Tsinghua University and Hongfujin Precision Industry (Shenzhen) Co., Ltd. establishes a close cooperative relationship and conducts exchanges, which weakens the limitation of spatial distance on knowledge transmission. In addition, Tsinghua University occupies a relatively central position in the cooperative network. This shows that universities represented by Tsinghua University possess critical knowledge resources, which plays an important role in promoting the evolution of the coinvention network for NEVs.

In the first two stages, the networks are relatively sparse. From the third period, however, the network begins to develop towards multipolarization. In the meanwhile, the partnerships between the nodes of the cooperative network have also been established substantially. Among the nodes, Dongguan Tafel New Energy Technology Co., Ltd. and Shenzhen Tafel New Energy Technology Co., Ltd. have established a constant and close relationship with each other and also maintain cooperation with multiple nodes. Moreover, Tsinghua University is still in the dominant position of the network for the diffusion of $R \& D$ related resources. It signifies that Shenzhen has reinforced the exchange of knowledge between different geographical regions. 


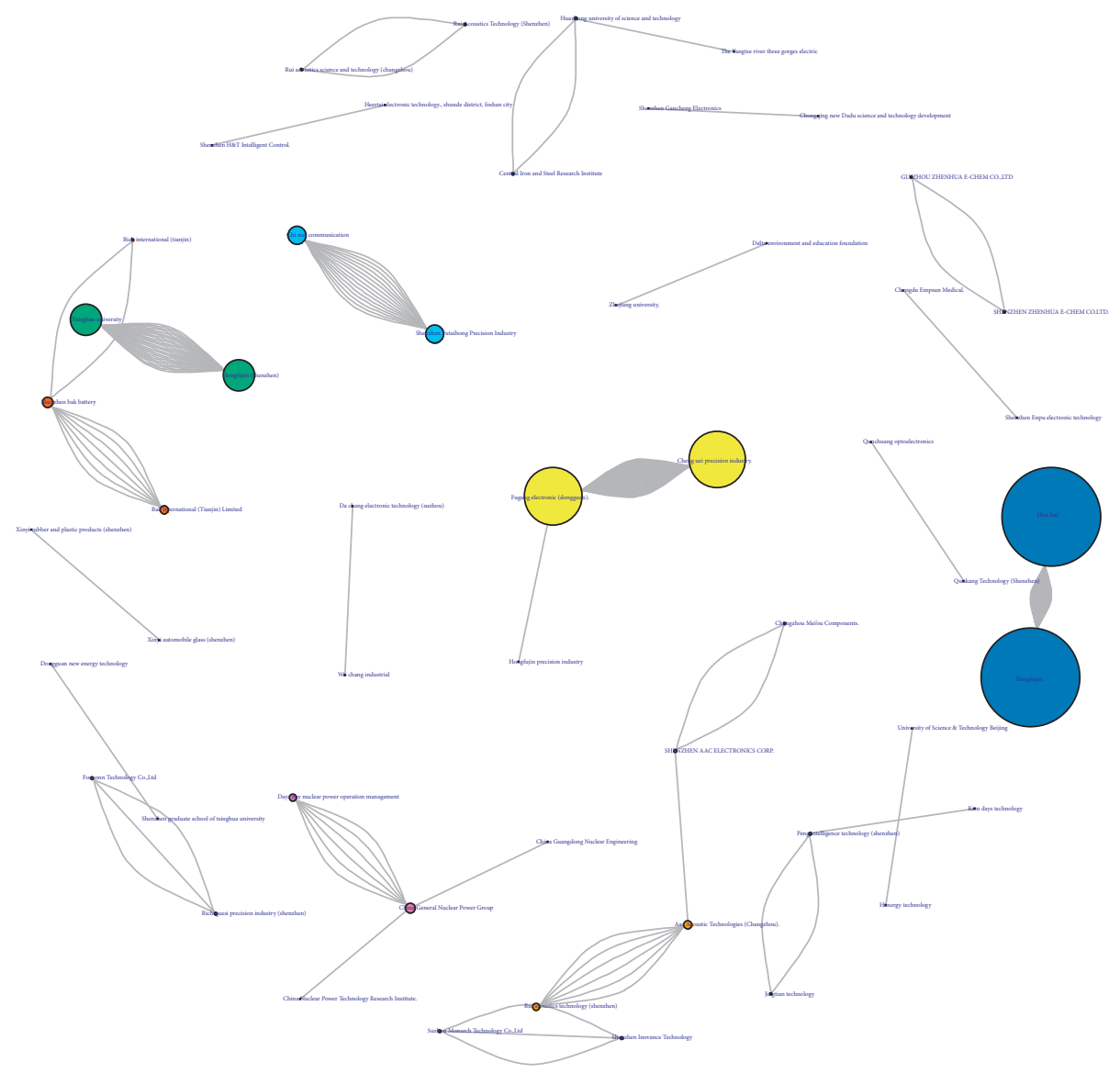

(a)

FIgURE 1: Continued. 


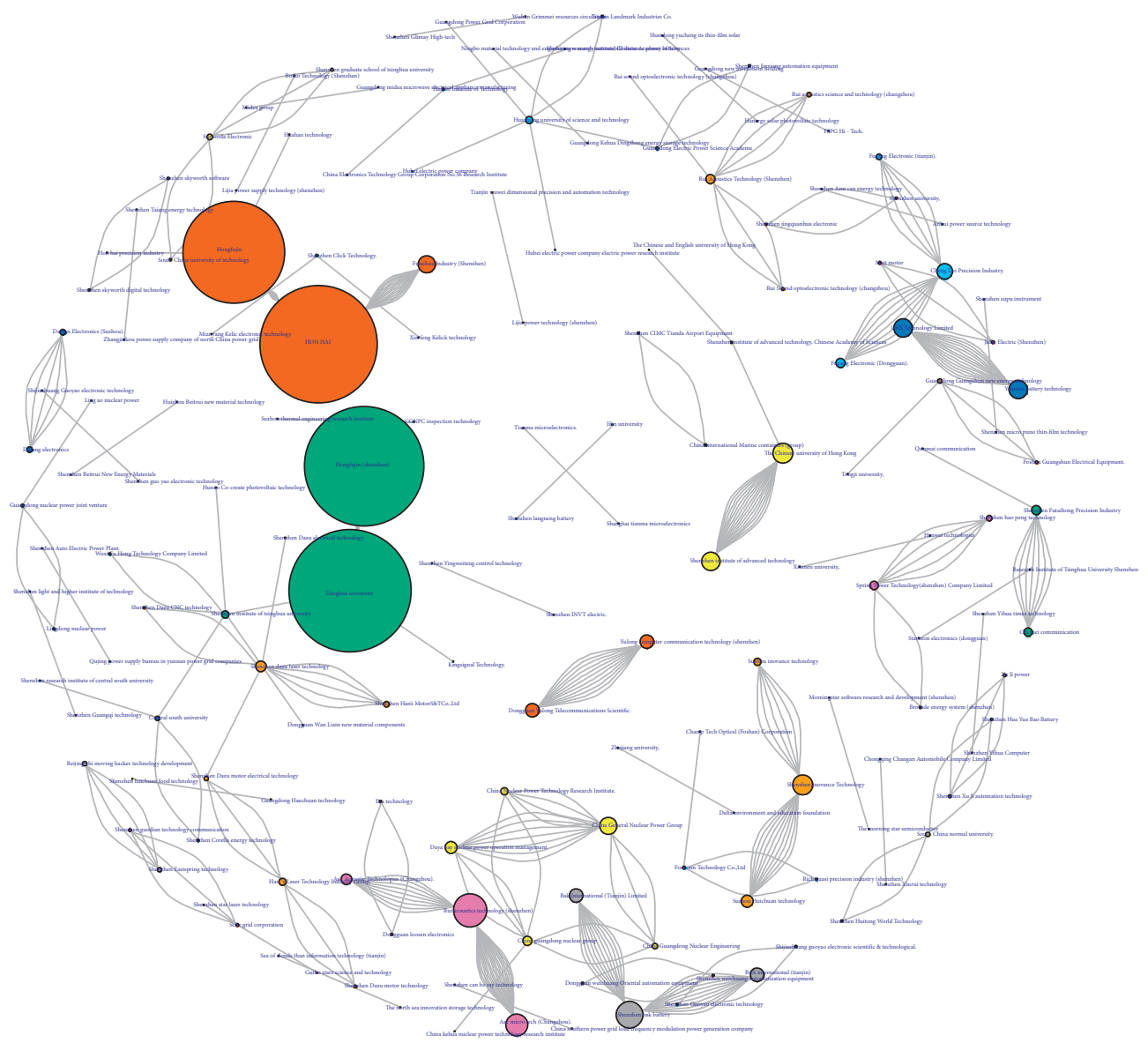

(b)

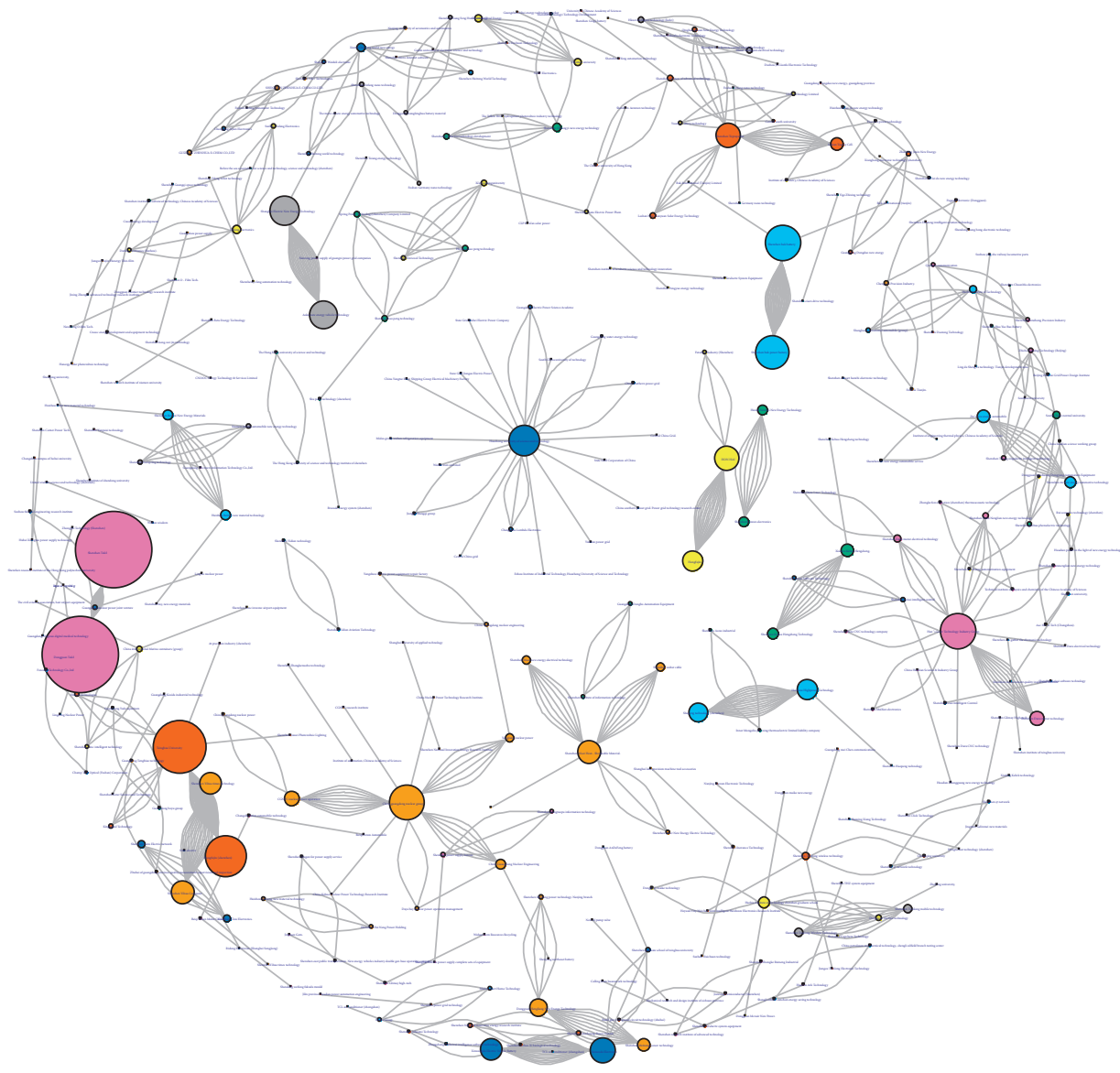

(c)

FIgURE 1: Topological evolution of NEVs coinvention network. (a) 2006-2009, (b) 2010-2013, (c) 2014-2017. 
4.2. Network Structure Analysis. We show the evolutionary process of the interorganizational coinvention network of NEVs by calculating multiple network indicators to illustrate the structural characteristics of the overall network, which is depicted in Table 1.

Network size means the number of organizations participating in the interorganizational network. As shown in Table 1, with the gradual development of NEVs coinvention activities, the network scale is expanding enormously. The number of nodes in the network increases from 52 in period 2006-2009 to 285 in period 2014-2017, and the network scale expands nearly 5 times. Network edges refer to the total number of relationships generated by the cooperation between nodes. As depicted in the above table, similar to network size, the number of network edges increases substantially, suggesting a continuously growing trend of the establishment of cooperative relationship in the network.

Network density reflects the overall connectivity level by dividing the number of actual ties by the number of maximum possible ties. A higher network density means a higher degree of connectivity between node cities in the network. As shown in Table 1, the increase speed of the network edge number is less than the expansion speed of the network scale, resulting in the decline of the network density from 0.0128 in the first stage to 0.0024 in the third stage. This reveals that the relationship between innovation entities is not particularly close.

Network diameter is the length of the largest geodesic path in the network. The smaller network diameter indicates that the cooperative network has higher transmission performance and efficiency. The average path length is the average value of the geodesic path length between any pair of nodes in the network. It can be observed that the cooperative network has a small average path length, and this indicator fluctuates between 1.1 and 1.3 over these three stages, indicating that cooperation and interaction between innovative organizations of the NEVs coinvention network are relatively frequent.

Average weighting is the average weighted value of all nodes. The value of this indicator is declining constantly over the whole period. The network's average clustering coefficient is the average of the clustering coefficients for all of the nodes. The small value of this indicator means that there are still some obstacles to establish cooperative relations between adjacent nodes. The common evaluation standard for the quality of community detection is the maximization of a benefit function called network modularity $Q$; when $Q$ approaches 1 , the community connectivity of a given network is strong. Remarkably, modularity increases from 0.713 in the first stage to 0.965 , and the value is continuously increasing in the past decade. This shows that Shenzhen's NEVs coinvention network is becoming more advanced and complex.

In order to further analyze the evolution of key nodes in Shenzhen's NEVs coinvention network, we use degree centrality and eigenvector centrality to reflect the importance of nodes in the network structure. The results are listed in Table 2.
It can be seen from Table 2 that, in the first stage, enterprises occupy the core position of Shenzhen's NEVs coinvention network. Hongfujin Precision Industry (Shenzhen) Co., Ltd. has the highest degree of degree centrality and eigenvector centrality. It signifies that Hongfujin Precision Industry (Shenzhen) Co., Ltd. has the most patent cooperation with other nodes in the NEVs field and is the center of knowledge diffusion in the network.

In the second stage, the degree centrality and eigenvector centrality of Tsinghua University is increasing, which indicates that it has become another important node in the network. In addition, Hongfujin Precision Industry (Shenzhen) Co., Ltd. is still a key node in the cooperative network with strong control ability. It has the largest number of partners and some nodes connected with it are also important nodes in the network, which means that there are more resources such as knowledge and information at its disposal.

For the 2006-2017 period, Tsinghua University is in a relatively central position, whereas Hongfujin Precision Industry (Shenzhen) Co., Ltd.'s position in the coinvention network is declining. In addition, it can be observed that in the third stage, Dongguan Tafel New Energy Technology Co., Ltd. and Shenzhen Tafel New Energy Technology Co., Ltd. also occupy the core positions. They have established close cooperative relations and carried out patent collaborations frequently. It signifies that Shenzhen has strengthened its geographical proximity with organizations within and beyond the city.

\section{Evolution of Determinants of Coinvention Network}

5.1. ERGM Specification. Links(dependent variable) is given by the absolute number of connections in the node. This variable is constructed from the total number of collaborations between institutions $a$ and $b$ during the process of technological production, in which the patent application has more than one inventor.

In order to verify the four hypotheses proposed in this paper about how coinnovation networks evolve, the following variables are given as follows:

(1) Geographical distance is measured as the logarithm of the physical distance between two organizations. This variable is introduced to test Hypothesis 1.

(2) Cognitive proximity is computed based on institutions' technology profiles. Each firm and organization's technology profile has been classified based on its IPC codes. The cognitive proximity between two institutions is obtained by calculating Pearson's correlation coefficients between their technology vectors, after which the values are min-max scaled. Two institutions with the highest similarity in technology profiles have a value equal to 1 , while the two institutions with the most different technology profiles have a value equal to 0 . This estimate is applied to test Hypothesis 2. 
TABLE 1: Topological structure indicators of NEVs coinvention network.

\begin{tabular}{|c|c|c|c|c|c|c|c|c|}
\hline Periods & $\begin{array}{l}\text { Network } \\
\text { size }\end{array}$ & $\begin{array}{c}\text { Number of } \\
\text { edges }\end{array}$ & $\begin{array}{c}\text { Network } \\
\text { density }\end{array}$ & $\begin{array}{l}\text { Network } \\
\text { diameter }\end{array}$ & $\begin{array}{l}\text { Average path } \\
\text { length }\end{array}$ & $\begin{array}{c}\text { Average } \\
\text { weighting degree }\end{array}$ & $\begin{array}{l}\text { Average clustering } \\
\text { coefficient }\end{array}$ & Modularity \\
\hline $2006-2009$ & 52 & 215 & 0.0128 & 2 & 1.15 & 8.27 & 0 & 0.7130 \\
\hline 2010-2013 & 154 & 470 & 0.0045 & 3 & 1.24 & 6.10 & 0 & 0.8140 \\
\hline 2014-2017 & 285 & 657 & 0.0024 & 3 & 1.16 & 4.61 & 0.0396 & 0.9655 \\
\hline
\end{tabular}

Table 2: Key nodes of the NEVs coinvention network.

\begin{tabular}{|c|c|c|}
\hline \multirow{2}{*}{ Periods } & \multicolumn{2}{|c|}{ The name of the node } \\
\hline & Sorted by degree centrality & Sorted by eigenvector centrality \\
\hline Phase one (2006-2009) & $\begin{array}{c}\text { Hongfujin Precision Industry (Shenzhen) Co., Ltd. } \\
\text { Hon Hi Precision Industry Co., Ltd. } \\
\text { Cheng Uei Precision Industry Co., Ltd. } \\
\text { Fugang Electronic (Dongguan) Co., Ltd. } \\
\text { Tsinghua University } \\
\end{array}$ & $\begin{array}{c}\text { Hongfujin Precision Industry (Shenzhen) Co., Ltd. } \\
\text { Hon hi Precision Industry Co., Ltd. } \\
\text { Tsinghua University } \\
\text { Cheng Uei Precision Industry Co., Ltd. } \\
\text { Chi Mei Communication Co., Ltd. } \\
\end{array}$ \\
\hline Phase two (2010-2013) & $\begin{array}{c}\text { Hongfujin Precision Industry (Shenzhen) Co., Ltd. } \\
\text { Tsinghua University } \\
\text { Hon Hi Precision Industry Co., Ld. } \\
\text { Rui Acoustics Technology (Shenzhen) Co., Ltd. } \\
\text { Rui Aoustics Science and Technology (Changzhou) Co., Ltd. }\end{array}$ & $\begin{array}{c}\text { Hongfujin Precision Industry (Shenzhen) Co., Ltd. } \\
\text { Tsinghua University } \\
\text { Hon Hi Precision Industry Co., Ltd. } \\
\text { Futaihua Industry (Shenzhen) Co., Ltd. } \\
\text { Huahan Technology Co., Ltd. }\end{array}$ \\
\hline Phase three (2014-2017) & $\begin{array}{c}\text { Dongguan Tafel New Energy Technology Co., Ltd. } \\
\text { Shenzhen Tafel New Energy Technology Co., Ltd. } \\
\text { Hongfujin Precision Industry (Shenzhen) Co., Ltd. } \\
\text { Tsinghua University } \\
\text { Han's Laser Technology Industry Group Co., Ltd. }\end{array}$ & $\begin{array}{l}\text { Dongguan Tafel New Energy Technology Co., Ltd. } \\
\text { Shenzhen Tafel New Energy Technology Co., Ltd. } \\
\text { Hongfujin Precision Industry (Shenzhen) Co., Ltd. } \\
\text { Tsinghua University } \\
\text { Han's Laser Technology Industry Group Co., Ltd. }\end{array}$ \\
\hline
\end{tabular}

(3) Organizational proximity is usually measured by two methods. The first one is whether enterprises belong to the same group company or parent company, that is, constrained by organizational structure and hierarchy [29]. The second measurement is by the degree of similar routine and incentive mechanism among enterprises [51]. Considering the limited number of cooperation between scientific research institutes in the NEVs industry and the amount number of cooperation between the parent company and its subsidiaries, head office, and branch company, we use the first method to construct the organizational proximity matrix. If two organizations belong to the parent-subsidiary relationship or are between the head office and the branch company, the value is 1 ; otherwise, it is 0 . This variable is introduced to test Hypothesis 3.

(4) Linguistic difference is set up to measure the cultural differences. This variable for cultural/linguistic difference is set to 1 when two institutions are located in different dialect areas. The partition of dialect areas of China is indexed from the 2010 Atlas of Chinese Dialects [52].

Other variables are also included in the ERGM analysis. Firmscale represents the size of firms, which is measured by the organizations' number of employees. Larger firms may be more likely to be tied to other organizations. Uniscale represents the size of universities, which is measured by the number of students in the school.
The above variables are categorized into three types following ERGM specification: Firmscale and Uniscale are node covariates. Geographical distance, Cognitive proximity, Linguistic difference, and organizational proximity are exogenous relational covariates. Mutual and Edges are an endogenous structure.

5.2. ERGM Results. The results of ERGM from 2006 to 2017 are presented in Table 3. Geographical distance is found to exhibit statistically negative impacts over the whole period and shows a decreasing effect. These results corroborate Hypothesis 1, signifying that geographical proximity plays an increasingly weaker role in the evolution of the collaborative network. In the meantime, with the deepening of collaborative innovation, the technological upgrading caused by knowledge exchange makes the organizations in the network more inclined to cognitive proximity and less dependent on geographical proximity. A possible explanation is that due to the construction of high-speed railways and airports since 2010, Shenzhen has strengthened its geographical proximity with cities within and beyond Guangdong province. Figure 1 also shows, in the second and third stage of the innovation network, that Rui Acoustics Technology (Shenzhen) Co., Ltd. has carried out extensive cooperation with Aac Microtech (Changzhou). Big companies such as Hongfujin Precision Industry (Shenzhen) Co., Ltd. have also established partnerships with Tsinghua University.

Concerning cognitive proximity, we find a positive overall trend, suggesting that closer cognitive base and 
TABLE 3: Cross-sectional ERGM results for interorganization coinvention network from 2006 to 2017.

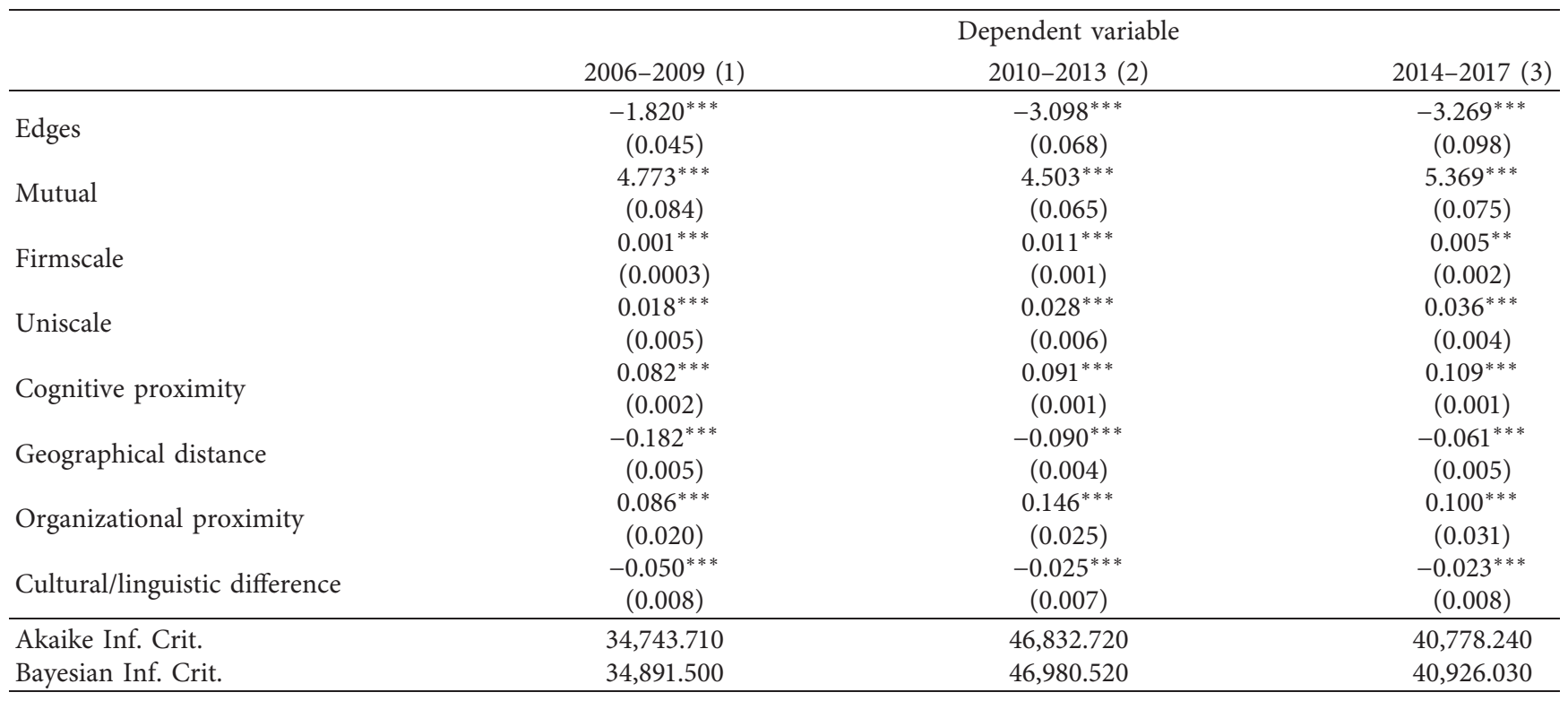

${ }^{* * *},{ }^{* *}$, and ${ }^{*}$ represent significance at the levels of $1 \%, 5 \%$, and $10 \%$, respectively.

values generate more links among the inventors of different organizations. In other words, it appears that increasing specialization outweighs interdisciplinarity, confirming Hypothesis 2. It demonstrates that the trend goes rather towards specialization in the NEVs coinvention activities in Shenzhen. This result is consistent with Broekel and Boschma's [23] investigation in the Dutch aviation industry and also corroborates the majority of literature that they do not find a change in the negative impact of cognitive distance over time on a global or national scale [42]. It is worth noting that, in recent years, as a result of the construction of highspeed railways and airports, as well as the establishment of cross-city branches of many renowned universities and research institutes (URIs), the strengthening of geographical proximity of Shenzhen with other cities has also facilitated cognitive proximity, such as knowledge interactions between researchers from different URIs.

With regard to organizational proximity, it is positively associated with the intensity of interorganizational scientific collaboration, indicating that there are many collaborations between parent and subsidiary companies or subsidiaries in NEVs coinvention network, such as Shenzhen Tafel New Energy Technology Co., Ltd. and Dongguan Tafel New Energy Technology Co., Ltd. This result corroborates Broekel and Boschma's [23] empirical result that organizational proximity is a driver behind the formation of knowledge network relationships. Therefore, Hypothesis 3 is supported.

In terms of dialect, similar to geographical distance, the impeding effect of cultural/linguistic difference is statistically significant and loses slight importance over time, providing evidence for Hypothesis 4. On the one hand, long-distance collaboration is often more valuable and involves the exchange of knowledge in high-level technological fields. Teixeira et al.'s [53] research demonstrated that projects that are more technologically advanced are geographically distant and culturally diversified, while those close to each other are inherently low tech. On the other hand, cultural difference is to some extent complemented by the increasing number of overseas returnees who have gained their degrees in foreign universities.

For node-level variables, the coefficients of Firmscale and Uniscale stay positive and significant over time, meaning that firms with larger size are prone to have more links as anticipated. The same applies to big universities. Besides, the significant coefficients of Edge and Mutual at the level of structural networks empirically confirm the correlation at this level. The negative coefficient of Edges is a common feature of social processes established networks, indicating that such networks exhibit less density than exponential random networks. Besides, the coefficient of Mutual is also positive and significant. It means that organizations tend to form connections with patterners that have similar degree centrality values. The result also indicates that triadic closure is a driving force in promoting the evolution of the interorganization coinvention networks.

\section{Conclusion and Discussion}

In order to study the structure and evolution of interorganizational scientific collaborations in the NEVs, this paper uses the coinvention data of Shenzhen, China, to construct the coinvention network of NEVs. The evolution pattern of coinvention activities from 2006 to 2017 is analyzed by using social network analysis. Then, we test our proposed evolutionary hypothesis with ERGM to investigate the dynamics of network influencing factors. The main conclusions of this paper are as follows.

First, the scale of coinvention network keeps expanding, and the cooperation depth between nodes has remarkably improved, which is featured with diversified cooperative entities. In addition, geographical distance shows a 
statistically negative but diminishing effect over the whole period. The ERGM results confirm our hypothesis that geographic proximity plays a weaker role in the evolution of cooperative networks. In the meanwhile, with regard to cognitive proximity, it presents a positive overall trend, indicating that closer cognitive bases and values generate more connections between inventors in different organizations. It demonstrates that, with the deepening of collaborative innovation, technological upgrading caused by knowledge exchange makes organizations in the network more inclined to cognitive proximity and less dependent on geographical proximity, which is consistent with most of the existing studies. Due to the construction of high-speed railways and airports, as well as the establishment of crosscity branches of many famous universities and research institutions (URIs), the reduction of Shenzhen's travel time to other cities also promotes cognitive proximity.

Secondly, in terms of organizational proximity, it is positively correlated with the intensity of interorganizational scientific cooperation. As far as dialects are concerned, similar to geographical distances, the impeding effect of cultural/ linguistic differences is statistically significant and has declined slightly in importance over time. Moreover, cultural differences are to some extent complemented by a growing number of returnees from overseas who have earned degrees at foreign universities. In addition, the result indicates that triadic closure is a driving force in promoting the evolution of the interorganizational coinvention networks.

For policy implications, firstly, the potential cooperation between innovation organizations in the field of NEVs needs to be fully explored. The establishment of a technology information sharing platform and the design of a cooperation innovation incentive mechanism would effectively shorten the technological distance and improve the efficiency of information transmission. Secondly, infrastructures that facilitate the flow of people and information, such as transportation and telecommunications, should be improved to facilitate the dissemination of technological information and the exchange of innovative talents, which would help expand the industrial clusters of cross-regional coinvention activities in Shenzhen's NEVs, especially for the industry-university-research collaborations. Thirdly, as the market share of NEVs continues to expand, the government should support technology opening and patent sharing, so as to further stimulate joint innovation vitality.

In terms of extension work, analysis on the level of individuals would help answer mechanisms behind the organizational-level network patterns. Nevertheless, our research provides a valuable explanation of the evolutionary mechanisms of knowledge cooperation activities among organizations in new energy technologies. The study of Shenzhen would also be of great interest in developing international comparisons within the same industry to be able to generalize more results of the work.

\section{Data Availability}

The data will be made available upon request to the corresponding author.

\section{Conflicts of Interest}

The authors declare that they have no conflicts of interest.

\section{Authors' Contributions}

Jia liu and Zhaohui Chong's contributions include the study design, data analysis and writing. Shijian Lu participated in the revision of the article.

\section{Acknowledgments}

This work is supported by Science and Technology Program of Guangdong Province (Grant No. 2020A1010020048), Science and Technology Program of Guangdong Province (Grant No. 2019A101002064), Natural Science Foundation of Guangdong (Grant No. 2018A030313453), Guangzhou Philosophy and Social Science Project (Grant No. 2019GZQN35), the Humanities and Social Science Fund of Ministry of Education of China (20YJC790189), National Statistical Science Research Program (2019510), Social Science Planning Project of Guangdong Province (Grant No. GD19YGL17), Science and Technology Program of Guangdong Province (2019-45;2019B101003021), The 13th Five-Year Plan of Education science in Guangdong Province (Grant No.2020GXJK213) and the Shantou University Scientific Research Foundation Project (Grant No. STF18010). The paper is also supported by the Natural Science Foundation of Basic and Applied Basic Research Foundation of Guangdong Province in 2021.

\section{References}

[1] X. Zhang and X. Bai, "Incentive policies from 2006 to 2016 and new energy vehicle adoption in 2010-2020 in China," Renewable and Sustainable Energy Reviews, vol. 70, pp. 24-43, 2017.

[2] L. Zhang and Q. Qin, "China's new energy vehicle policies: evolution, comparison and recommendation," Transportation Research Part A: Policy and Practice, vol. 110, pp. 57-72, 2018.

[3] L. Zhang, L. Wang, and J. Chai, "Influence of new energy vehicle subsidy policy on emission reduction of atmospheric pollutants: a case study of Beijing, China," Journal of Cleaner Production, vol. 275, Article ID 124069, 2020.

[4] X. Yuan, X. Liu, and J. Zuo, "The development of new energy vehicles for a sustainable future: a review," Renewable and Sustainable Energy Reviews, vol. 42, pp. 298-305, 2015.

[5] J. Ruan, P. D. Walker, N. Zhang, and J. Wu, "An investigation of hybrid energy storage system in multi-speed electric vehicle," Energy, vol. 140, pp. 291-306, 2017.

[6] Z. Song, J. Hou, H. Hofmann, J. Li, and M. Ouyang, "Slidingmode and Lyapunov function-based control for battery/ supercapacitor hybrid energy storage system used in electric vehicles," Energy, vol. 122, pp. 601-612, 2017.

[7] J. Knoben and L. A. G. Oerlemans, "Proximity and interorganizational collaboration: a literature review," International Journal of Management Reviews, vol. 8, no. 2, pp. 71-89, 2006.

[8] X.-P. Lei, Z.-Y. Zhao, X. Zhang et al., “Technological collaboration patterns in solar cell industry based on patent inventors and assignees analysis," Scientometrics, vol. 96, no. 2, pp. 427-441, 2013. 
[9] V. A. Omelianenko, "Analysis of potential of international inter-cluster cooperation in high-tech industries," International Journal of Econometrics and Financial Management, vol. 2, 2014.

[10] H. Choe, D. H. Lee, I. W. Seo, and H. D. Kim, "Patent citation network analysis for the domain of organic photovoltaic cells: country, institution, and technology field," Renewable and Sustainable Energy Reviews, vol. 26, pp. 492-505, 2013.

[11] J. Zheng, Z.-Y. Zhao, X. Zhang, D.-Z. Chen, and M.-H. Huang, "International collaboration development in nanotechnology: a perspective of patent network analysis," Scientometrics, vol. 98, no. 1, pp. 683-702, 2014.

[12] Y. Sun and K. Liu, "Proximity effect, preferential attachment and path dependence in inter-regional network: a case of China's technology transaction," Scientometrics, vol. 108, no. 1, pp. 201-220, 2016.

[13] A. F. De Paulo, E. M. S. Ribeiro, and G. S. Porto, "Mapping countries cooperation networks in photovoltaic technology development based on patent analysis," Scientometrics, vol. 117 , no. 2 , pp. $667-686,2018$

[14] M. Åmman, "Government policy and the development of electric vehicles in Japan," Energy Policy, vol. 34, no. 4, pp. 433-443, 2006.

[15] J. Wang and G. Zhu, "Joint-patent analysis of industry and university collaboration of new energy vehicle industry," Forum on Science and Technology in China, vol. 1, pp. 37-43, 2012.

[16] T. B. Christensen, "Modularised eco-innovation in the auto industry," Journal of Cleaner Production, vol. 19, no. 2-3, pp. 212-220, 2011.

[17] A. M. Andwari, A. Pesiridis, S. Rajoo et al., "A review of Battery Electric Vehicle technology and readiness levels," Renewable and Sustainable Energy Reviews, vol. 78, pp. 414430, 2017.

[18] G. E. Haslam, J. Jupesta, and G. Parayil, "Assessing fuel cell vehicle innovation and the role of policy in Japan, Korea, and China," International Journal of Hydrogen Energy, vol. 37, no. 19, pp. 14612-14623, 2012.

[19] J. Ren, "New energy vehicle in China for sustainable development: analysis of success factors and strategic implications," Transportation Research Part D: Transport and Environment, vol. 59, pp. 268-288, 2018.

[20] H. Sun, Y. Geng, L. Hu, L. Shi, and T. Xu, "Measuring China's new energy vehicle patents: a social network analysis approach," Energy, vol. 153, pp. 685-693, 2018.

[21] X. Cao, C. Li, W. Chen et al., "Research on the invulnerability and optimization of the technical cooperation innovation network based on the patent perspective-a case study of new energy vehicles," PLoS One, vol. 15, no. 9, Article ID e0238541, 2020.

[22] A. Aguiléra, V. Lethiais, and A. Rallet, "Spatial and non-spatial proximities in inter-firm relations: an empirical analysis," Industry and Innovation, vol. 19, no. 3, pp. 187-202, 2020.

[23] T. Broekel and R. Boschma, "Knowledge networks in the Dutch aviation industry: the proximity paradox," Journal of Economic Geography, vol. 12, no. 2, pp. 409-433, 2011.

[24] P.-A. Balland, M. De Vaan, and R. Boschma, "The dynamics of interfirm networks along the industry life cycle: the case of the global video game industry, 1987-2007," Journal of Economic Geography, vol. 13, no. 5, pp. 741-765, 2013.

[25] L. Cassi and A. Plunket, "Proximity, network formation and inventive performance: in search of the proximity paradox," The Annals of Regional Science, vol. 53, no. 2, pp. 395-422, 2014.
[26] P.-A. Balland, J. A. Belso-Martínez, and A. Morrison, "The dynamics of technical and business knowledge networks in industrial clusters: embeddedness, status, or proximity?" Economic Geography, vol. 92, no. 1, pp. 35-60, 2016.

[27] F. Crespin-Mazet, K. Goglio-Primard, and F. Scheid, "Open innovation processes within clusters - the role oftertius iugens," Management Decision, vol. 51, no. 8, pp. 1701-1715, 2013.

[28] L. Shi, X. Xiang, W. Zhu, and L. Gao, "Standardization of the evaluation index system for low-carbon cities in China: a case study of Xiamen," Sustainability, vol. 10, no. 10, p. 3751, 2018.

[29] Z. Cao, B. Derudder, and Z. Peng, "Interaction between different forms of proximity in inter-organizational scientific collaboration: the case of medical sciences research network in the Yangtze River Delta region," Papers in Regional Science, vol. 98, no. 5, pp. 1903-1924, 2019.

[30] M. M. Fischer, T. Scherngell, and E. Jansenberger, "The geography of knowledge spillovers between high-technology firms in Europe: evidence from a spatial interaction modeling perspective," Geographical Analysis, vol. 38, no. 3, pp. 288-309, 2006.

[31] C. S. Hazir and C. Autant-Bernard, "Determinants of crossregional R\&D collaboration: some empirical evidence from Europe in biotechnology," The Annals of Regional Science, vol. 53, no. 2, pp. 369-393, 2014.

[32] L. Shi, X. Xiang, W. Zhu, and L. Gao, "Standardization of the evaluation index system for low-carbon cities in China: a case study of Xiamen," Sustainability, vol. 10, no. 10, p. 3751, 2018.

[33] C. Geldes, C. Felzensztein, E. Turkina, and A. Durand, "How does proximity affect interfirm marketing cooperation? A study of an agribusiness cluster," Journal of Business Research, vol. 68, no. 2, pp. 263-272, 2015.

[34] J. Gaspar and E. L. Glaeser, "Information technology and the future of cities," Journal of Urban Economics, vol. 43, no. 1, pp. 136-156, 1998.

[35] R. Narula and A. Zanfei, "Globalisation of innovation," Handbook of Innovation, vol. 19, pp. 318-345, 2005.

[36] L. Picci, "The internationalization of inventive activity: a gravity model using patent data," Research Policy, vol. 39, no. 8, pp. 1070-1081, 2010.

[37] R. Hassink, "How to unlock regional economies from path dependency? From learning region to learning cluster," European Planning Studies, vol. 13, no. 4, pp. 521-535, 2005.

[38] A. Capaldo and A. M. Petruzzelli, "Partner geographic and organizational proximity and the innovative performance of knowledge-creating alliances," European Management Review, vol. 11, no. 1, pp. 63-84, 2014.

[39] E. Marrocu, R. Paci, and S. Usai, "Productivity growth in the old and new Europe: the role of agglomeration externalities," Journal of Regional Science, vol. 53, no. 3, pp. 418-442, 2013.

[40] B. Nooteboom, W. Van Haverbeke, G. Duysters, V. Gilsing, and A. Van Den Oord, "Optimal cognitive distance and absorptive capacity," Research Policy, vol. 36, no. 7, pp. 1016-1034, 2007.

[41] X. Dong, S. Zheng, and M. E. Kahn, "The role of transportation speed in facilitating high skilled teamwork across cities," Journal of Urban Economics, vol. 115, Article ID 103212, 2020.

[42] R. Lata, S. Von Proff, and T. Brenner, "The influence of distance types on co-patenting and co-publishing in the USA and Europe over time," The Annals of Regional Science, vol. 61, no. 1, pp. 1-23, 2018.

[43] Y. Gong, I. H.-S. Chow, and D. Ahlstrom, "Cultural diversity in China: dialect, job embeddedness, and turnover," Asia 
Pacific Journal of Management, vol. 28, no. 2, pp. 221-238, 2011.

[44] C. Zhang, "The Chinese mosaic: cultural diversity and creative cities," Journal of Regional Science, vol. 59, no. 2, pp. 214-227, 2019.

[45] J. Norman, Chinese, Cambridge University Press, Cambridge, UK, 1988.

[46] A. Barrat, M. Barthelemy, R. Pastor-Satorras, and A. Vespignani, "The architecture of complex weighted networks," Proceedings of the National Academy of Sciences, vol. 101, no. 11, pp. 3747-3752, 2004.

[47] L. C. Freeman, "Centrality in social networks conceptual clarification," Social Networks, vol. 1, no. 3, pp. 215-239, 1978.

[48] G. Robins, P. Pattison, Y. Kalish, and D. Lusher, "An introduction to exponential random graph $\left(\mathrm{p}^{*}\right)$ models for social networks," Social Networks, vol. 29, no. 2, pp. 173-191, 2007.

[49] S. Wasserman and P. Pattison, "Logit models and logistic regressions for social networks: I. An introduction to Markov graphs andp," Psychometrika, vol. 61, no. 3, pp. 401-425, 1996.

[50] D. Lusher, J. Koskinen, and G. Robins, Exponential Random Graph Models, Social sciences Academic Press, New York, NY, USA, 2016.

[51] L. Lazzeretti and F. Capone, "R\&D networks in high technology applied to cultural goods A social network analysis," Sinergie Italian Journal of Management, vol. 34, no. 5, p. 105122, 2015.

[52] Z. H. Xiong and Z. X. Zhang, Language Atlas of China, Commercial Press, Beijing, China, 2012.

[53] A. A. C. Teixeira, P. Santos, and A. Oliveira Brochado, "International R\&D cooperation between low-tech SMEs: the role of cultural and geographical proximity," European Planning Studies, vol. 16, no. 6, pp. 785-810, 2008. 